\title{
Modelling Dialogue and Beliefs as a Basis for Generating Guidance in a CSCL Environment
}

\author{
Kristine Lund ${ }^{1}$, Michael Baker ${ }^{1}$ and Monique Baron ${ }^{2}$ \\ ${ }^{1}$ C.N.R.S.-GRIC-COAST, ENSL, France. lund@ens-lyon.fr, mbaker@ens-lyon.fr \\ ${ }^{2}$ LAFORIA, Université Pierre et Marie Curie, Paris, France. baron@laforia.ibp.fr
}

\begin{abstract}
Existing approaches to integrating ITS and CSCL environments have not attempted to model the collaborative interaction between human learners in order to exploit its pedagogical potential. We present an approach to modelling such interactions and students' underlying beliefs, within the framework of a CSCL environment designed for learning the concept of energy in physics (C-CHENE). The environment is based on flexible structuring of the collaborative interaction using a specially designed communication interface, and a dialogue grammar. We propose three types of automatic guidance that could be provided on this basis.
\end{abstract}

\section{Introduction}

Although CSCL designers have usually concentrated on designing tools for collaborative interaction, some attempts have been made to integrate aspects of $\mathrm{AI}$ and Education research into collaborative educational environments (e.g. [6], [10], [13]). Nevertheless, these systems have not yet attempted to exploit the pedagogical potential of the interaction between human learners. The goal of this paper is therefore to describe an approach to modelling the interaction between collaborative human learners and their underlying beliefs, with a view to generating guidance within the framework of an architecture of a CSCL environment called "C-CHENE"1, designed for teaching the concept of energy in physics.

We view the students' collaborative interaction both as a source from which students' beliefs can be (partially) inferred, and as a 'domain' to be modelled and 'tutored' in its own right. The latter depends on identifying and encouraging the occurrence of interaction forms that favour learning, such as "giving reasons/explanations [7], joint participation and productive resolution of conflicts. Our approach - termed flexible structuring - involves constraining the students' interaction by providing a limited set of dialogue moves (in the form of buttons or menu items to be selected), whose design was based on analysis of 'free' network interactions and explicit models of collaborative dialogue ([5], [1]). Use of particular dialogue moves is not however enforced, as in approaches based on interaction "scripting" (e.g. [22]), or normative dialogue grammars [18]. This leaves open the question as to when a particular form of the interaction should be imposed automatically by the system. More generally, such a communication interface based on graphical interaction lightens students' typing load, thus enabling them to concentrate on a more knowledge-based interaction. From the

\footnotetext{
1 "C-CHENE" = Collaborative "CHaîne ENErgétique"/"Energy Chain".
} 
system's point of view, some natural language understanding problems can be avoided.

After describing the general architecture of C-CHENE, we focus on two of its components : the communication interface, with its underlying dialogue model, and belief inference mechanisms. In conclusion we describe automatic guidance strategies that could operate on the basis of these components, and describe future work.

\section{C-CHENE - a CSCL Environment for Learning Modelling in Physics}

C-CHENE was developed as an experimental CSCL environment, within the framework of a long-term research project on teaching and (collaborative) learning of modelling in physics. Previous research has been carried out on analysing and AI modelling of students' modelling processes ([21], [9], [4]).

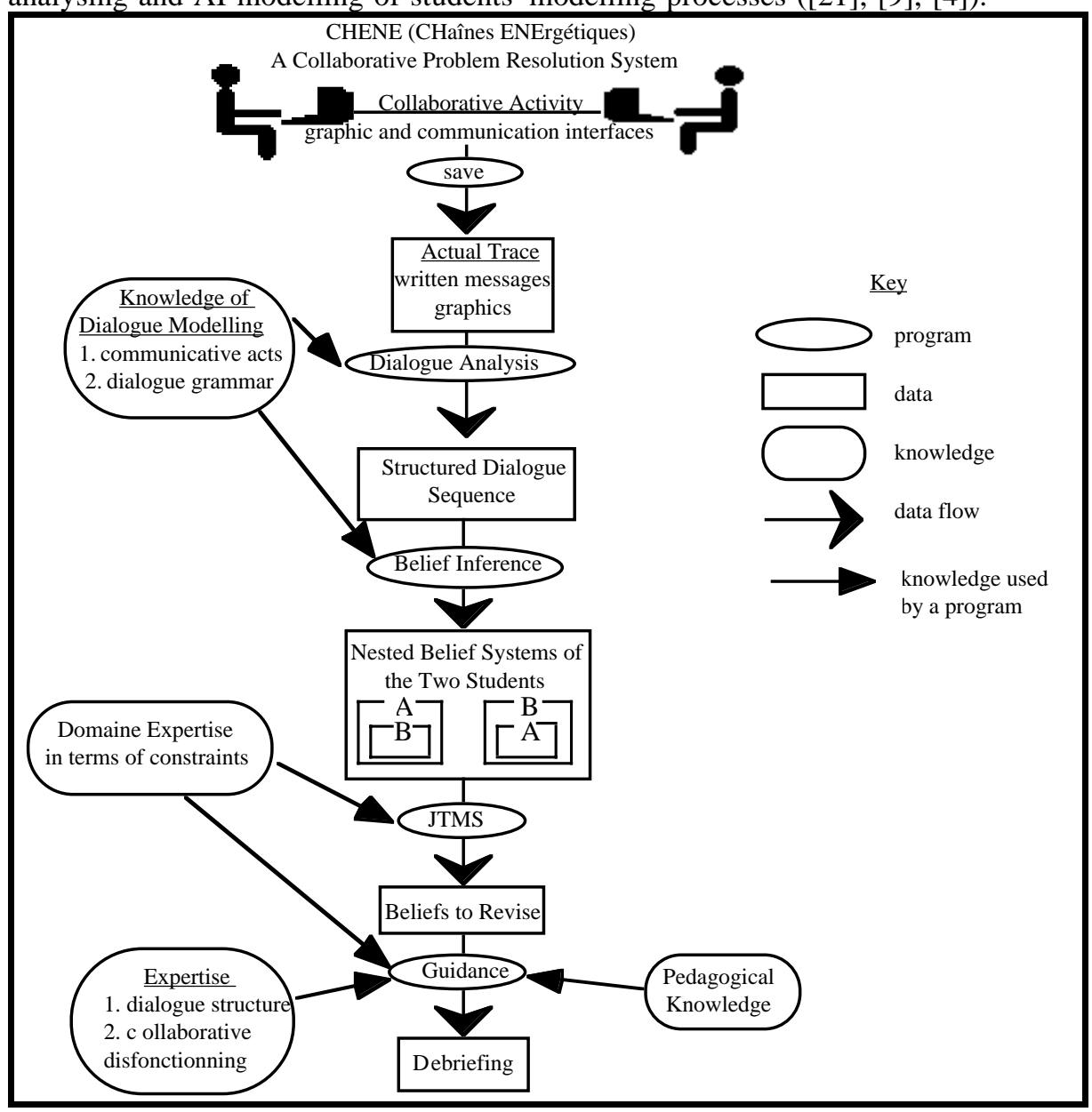

Fig. 1 C-CHENE architecture 
The task studied requires students (16-17 years old) to (co-)construct qualitative models for energy storage, transfer and transformation for simple experiments ("energy chains") ${ }^{2}$, using a specially designed graphical interface. Students worked in pairs at a distance in a network (SUN / ShowMe), each having their own physics experiment available, a text describing the problems to be solved, as well as the same graphical and specially designed communication interfaces projected simultaneously onto his/her personal computer screen.

The architecture of C-CHENE can be understood by following the data flow from the top to the bottom of Figure 1. Collaborative activity is carried out within the communication and graphic (energy chain construction) interfaces (see Figure 2). The resulting student interaction (communicative acts - "CA"s) and energy chain constructions (graphical interface actions) are written to a file as they occur. The full trace of the collaborative problem-solving activity is then structured according to a normative dialogue grammar (see §3). Dialogue analysis and belief inference is begun at the end of a problem-solving session. Beliefs are inferred on the assumption that graphical interface actions imply agents' beliefs in the change of state produced, and on the basis of standard sincerity conditions and effects of CAs, with their relations to the previous interaction.

Students' beliefs spaces are then entered into a JTMS [11]. Any incoherencies with the theory of energy in physics are tagged. Opportunities for providing guidance are then identified based on the structured trace, the dialogue grammar and representations of the students' belief systems (see §5).

\section{Designing and Modelling the Collaborative Problem-solving Interaction}

Figure 2 shows the communication interface (redrawn - the original is in French). The upper section of the screen shows the area for energy chain construction (with appropriate menus), and the lower the communication area. The lower part of the communication area contains a set of buttons to be used by both students for performing different communicative acts, and the upper part the ongoing interaction history displayed for the students. The interaction history is viewed as an important resource in collaborative dialogue since it provides a common objective reference to previous activity that may encourage reflection and more effective collaboration ([8], [15]).

Providing a limited set of buttons was intended to ease the typing load as well as encourage the students to engage in certain preferred communicative activities (e.g. using the [Because ...] button to give reasons and explanations for intermediary solutions). It was not obvious to us that the students would be able to introspect on and 'classify' their own communicative actions. Analysis of interaction transcripts, however, showed that the [I think that ... ] button (a 'catch-all') was used infrequently, and that where students could type free text,

2 See upper part of Figure 2 for an (erroneous) example of an energy chain constructed by two students for a circuit where a bulb is connected to a battery by two wires. 
the communicative act actually realised corresponded generally to that stipulated by the CA button concerned.

The set of CA buttons provided was designed on the basis of analysis of a corpus of 'chat-box' interactions with C-CHENE using existing models for conversation [16], information dialogues [5] and collaborative problem-solving dialogues [1].

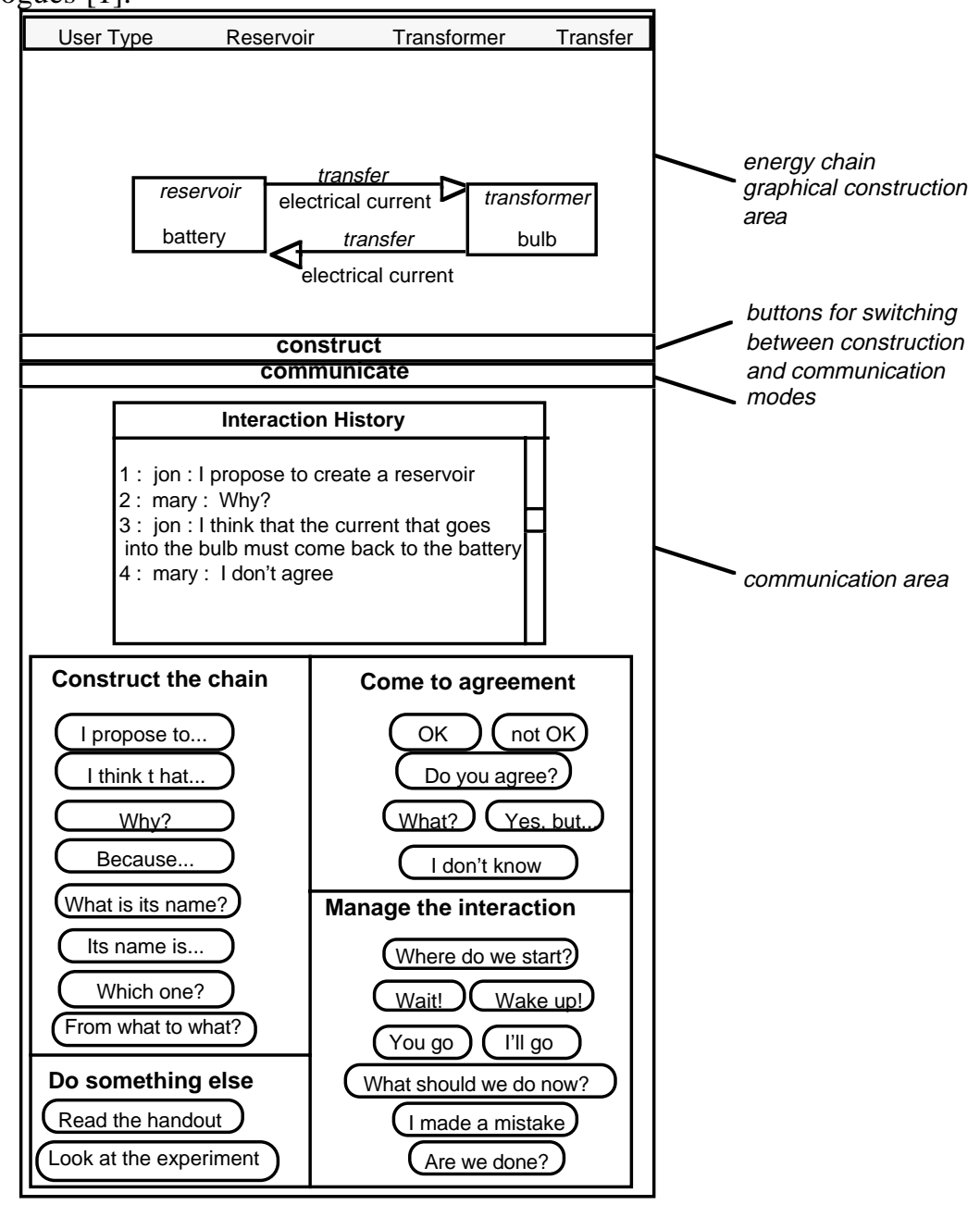

Fig. 2 C-CHENE communication and graphics interfaces

Three fundamental distinctions are drawn upon in the design of the interface :

(1) Task-oriented CAs, whose primary function is to accomplish the dialogueexternal task (e.g. transfer of information, problem-solving), are distinguished from dialogue control CAs, whose function is to keep the dialogue itself 'on track' (e.g. attitudinal reactions such as [Ok] or [Not Ok], perception and understanding, dialogue structuring such as opening and closing). This distinction 
is reflected in the organisation of the two basic columns of buttons in the communication interface (task-oriented $=$ left column $;$ dialogue control $=$ right column).

(2) Initiative / reactive CAs. This distinction is reflected in the different types of semantic content of CAs. Initiative acts, such as [I propose to ...], or [Its name is ...] generally introduce a new propositional content, determined here by selection on a hierarchical set of menus that are displayed once the CA button is clicked (e.g. following [I propose to ...], the student can select one of $\{<$ create a reservoir>, <create a transformer>, ...\}). Other acts refer either to the dialogue itself (e.g. [Are we done ?]), or, in the case of reactive CAs, to propositions expressed in previous CAs (e.g. [Why?]). Finally, some CAs have a content that is a (presently unanalysed) free text string (e.g. [I think that...]).

(3) We draw on the well-known distinction between different types of illocutionary acts (e.g. QUESTION function, REQUEST function, ASSERTION function, etc.), each of which has specific sincerity conditions and effects on the dialogue context.

In terms of these three distinctions, the specific CA "[I propose to ...]<create a reservoir $>$ " is, for example, task-oriented (it aims to achieve the problemsolving task), initiative (it does not react to a previous CA), and has an OFFER communicative function (see [1]). Its most characteristic sincerity condition is : "Speaker believes that if Hearer accepts that Speaker performs action p, then Speaker will perform it".

However, the standard attitudes underlying CAs, considered in isolation from their insertion in the dialogue sequence, are insufficient for inferring all the relevant attitudes, precisely because certain acts relate to previous ones. Consider Figure 3, taken from a collaborative problem-solving session involving real students.

1: A : [I propose to...] <create a transfer>

2: B : [Why?]

3: A : [ I think that...] "the current that goes into the bulb must come back to the battery"

4: B : [I don't agree]

Fig. 3 Example dialogue sequence

Apart from the problem of determining the identity of the transfer mentioned in line 1 , should the system assume from line 4 that student B does not agree with the reason student $\mathrm{A}$ gives for the proposed transfer creation, or rather that the student does agree with the reason given, but not that it constitutes a justification of the first proposal. This example illustrates the necessity of maintaining a relational if not hierarchical representation of a dialogue ([14], [16]) from which a system can infer beliefs. Awaiting construction of such a complete representation, this necessity can be obviated in part by constraining the possible relations using a normative dialogue grammar, as described below.

Although it is highly questionable as to whether there could be a descriptive grammar of dialogue (see e.g. [12]), it is nevertheless possible to define a normative one, i.e. one to which a given natural dialogue is expected, or constrained, to conform. In our case, such a normative grammar is designed to 
constrain the students to certain forms of interaction that favour learning (in conjunction with the guidance generation module), and to facilitate inference of students' beliefs. We therefore term the grammar "Dialogue For Learning" (DFL).

\begin{tabular}{ll}
\hline current CA under analysis & possible relations to previous CA's \\
\hline ASSERT & ASSERT, OFFER, REQUEST \\
OFFER & OFFER \\
REQUEST & ASSERT, OFFER \\
\hline
\end{tabular}

Fig. 4 Selected examples of relations between communicative acts

DFL is largely based on Sitter \& Stein's [20] ATN-network for informationseeking dialogues. The edges in the network are the communicative acts available in C-CHENE's communication interface. Figure 4 shows part of the grammar ; the first column shows the current $\mathrm{CA}$ under analysis, and the second a set of CAs produced in the previous dialogue to which it could relate. In traversing the network, the system gathers some of the relations between the communicative acts in the dialogue.

\begin{tabular}{|c|c|c|c|c|c|}
\hline & \multicolumn{5}{|c|}{ dialogue $(A, B)$} \\
\hline & \multicolumn{4}{|c|}{ offer $(A, B)$} & reject $(B, A)$ \\
\hline \multirow[b]{3}{*}{$\begin{array}{l}\text { A : offer } \\
\text { [l propose } \\
\text { to...] } \\
\text { [create a } \\
\text { transfer] }\end{array}$} & & alogue (B,A, sol & cit contextual it & nformation) & \multirow[b]{3}{*}{$\begin{array}{l}\text { B : reject } \\
\text { [I don't } \\
\text { agree] }\end{array}$} \\
\hline & request $(B, A)$ & promise $(A, B)$ & assert $(A, B)$ & $\begin{array}{c}\text { be discontented } \\
(B, A)\end{array}$ & \\
\hline & $\begin{array}{l}\text { B : request } \\
\text { Why? }\end{array}$ & (jump) & $\begin{array}{l}\text { A : assert } \\
\text { [I think that...] } \\
\text { the current } \\
\text { that goes into } \\
\text { the bulb must } \\
\text { come back to } \\
\text { the battery }\end{array}$ & (jump) & \\
\hline
\end{tabular}

Fig. 5 Representation of dialogue grammar relations shown in Figure 4

Figure 5 shows relations between CAs for the example dialogue sequence of Figure 3 , in the formalism of Sitter and Stein (op.cit.). The relevant part of the DFL is, however, insufficient alone to establish precisely these relations, since the grammar only defines a space of previous CAs to which the current one could relate. Thus, for example, the REQUEST of line 2 (Figure 3) could, according to Figure 4, relate back to either an ASSERT or an OFFER. In this case, given that only this sequence is being analysed, the OFFER (line 1) is selected as the only possibility. On other occasions, heuristics must be used to select between alternatives. For example, the ASSERT of line 3 is assumed to be providing the information requested in line 2, rather than being an assertion that elaborates on the offer of 1 , since 2 is more recent. 


\section{Inferring and Maintaining Students' Beliefs}

The beliefs that could be inferred from the example dialogue sequence in Figure 3 are shown in Figure 6. For example, the last column last line (inferred from line 4 in Figure 3) shows that C-CHENE has no information concerning student B's beliefs about the object "current". In addition, C-CHENE believes that student B does not believe that transfer3 should go from the bulb to the battery. The first column and line reflects the fact that student A is aware of student B's beliefs.

C-CHENE represents beliefs attributed to each of the students, including those that the students are held to ascribe to each other. Beliefs are nested in the manner described by Ballim and Wilks [2], each belief being grouped according to the topic of its proposition and the agent who possesses it. Without natural language interpretation, DFL is unable to tag all relevant justifications as such. The beliefs and justifications that are inferred (propositions or text strings) are placed into a dependency network using a JTMS.

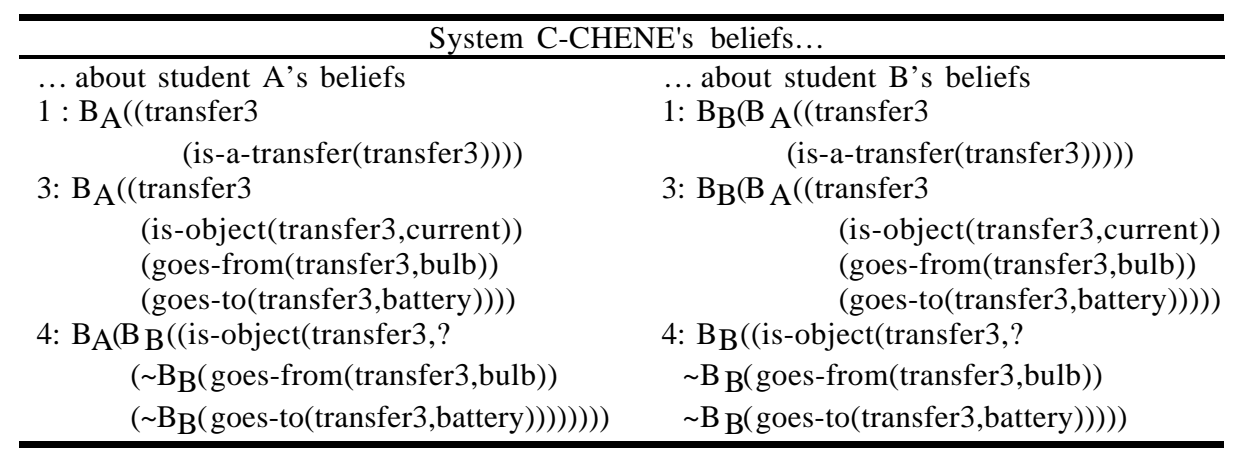

Fig. 6 The students' beliefs inferred from the dialogue example

Several problems for students' belief modelling in CSCL, well identified for student modelling in classical ITS systems (see e.g. [3], [19]), must be dealt with, such as :

- modification of a student's belief space after (s)he changes his/her mind ;

- modification of a student's belief space subsequent to different types of guidance ;

- ramifications of the above modifications for the rest of the belief space.

The beliefs inferred by C-CHENE are necessarily incomplete which means that any guidance based on this inference must necessarily be non-directive or negotiative [17].

\section{Guidance Strategies}

We propose three main bases on which these architectural components could be used for generating guidance :

(1) domain-related beliefs - detecting and pointing out "no-goods" between students' beliefs and the domain-rules for modelling energy in physics ; 
(2) collaborative interaction forms - 'preferring' interactions where for example :

- both partners make relatively equal contributions to problem solving,

- partners propose explanations for intermediary problem solutions (externalisation reflection $\rightarrow$ cognitive change),

- domain-related CAs occur to a greater extent than interaction-control CAs.

(3) communication problems - helping to resolve 'discrepancies' between students' models of each others' beliefs (miscomprehensions), from the system's point of view.

In addition, the display of the dialogue history provided for students can be exploited here, since failure to take into account previous statements or actions in the ongoing discussion can be pointed out.

\section{Conclusions and Further Work}

At the present state of our research, the new communication interface, specially adapted to the architecture of C-CHENE, has been implemented and experimented with groups of students. The set of communicative acts has been defined and represented, as has the dialogue grammar. An experimental belief system has been implemented, and appropriate belief inference and maintenance mechanisms are still being specified, in close relation with analysis of the dialogue transcripts produced in the experiments. So far we have nevertheless been able to progress with specification of the complete architecture and to identify some of the major research problems to be addressed, including the identification of relations between dialogue utterances and the implications of this problem for belief inference. These are difficult problems given that most existing work on belief system already assumes beliefs to be derived, and thus concentrates on the internal maintenance mechanisms. Our future research will therefore concentrate on refining the existing belief inference and maintenance techniques, and on developing/evaluating the above mentioned mechanisms for detecting opportunities for providing educational guidance.

\section{Acknowledgements}

We would like to thank members of the COAST research team for assistance in carrying out experiments with students, and Andrée Tiberghien for comments on an earlier draft. This research is financed by the C.N.R.S and is based in part on K. Lund's DEA thesis, supervised by M. Baker and M. Baron.

\section{References}

1. Baker, M.: A Model for Negotiation in Teaching-Learning Dialogues. Journal of Artificial Intelligence in Education, 5 (2), (1994) 199-254.

2. Ballim. A., \& Wilks, Y.: Artificial Believers, The Ascription of Belief. Hillsdale, New Jersey : Lawrence Erlbaum Associates. (1991)

3. Baron, M.: Quelques problèmes de nonmonotonie en EIAO, Actes du ler Colloque Européen Intelligence Artificielle et Formation. Applica 88, (1988) 143-155. 
4. Bental, D., Brna, P.: Enabling Abstractions: Key Steps in Building Physics Models. The Proceedings of Artificial Intelligence in Education, August, Washington, D.C. (1995) 162-169.

5. Bunt, H.C.: Information Dialogues as Communicative Action in Relation to Partner Modelling and Information Processing. In M.M. Taylor, F. Néel, D.G. Bouwhuis (Eds.), Human Factors in Information Technology 4, The Structure of Multimodal Dialogue. Amsterdam: Elsevier Science Publishers B.V. (1989)

6. Chan, T.W., Chou, C.Y., Lee, M.F., Chang, M.H.: Reciprocal-tutoring-kids: Tutortutee role playing systems. The Proceedings of Artificial Intelligence in Education, August, Washington, D.C. (1995) 226-233.

7. Chi, M.T.H., Bassok, M., Lewis, M.W., Reimann, P. \& Glaser, R.: Self-explanations : How Students Study and Use Examples in Learning to Solve Problems. Cognitive Science 13 (2). (1989) 145-182.

8. Collins, A. \& Brown, J.S.: The computer as a tool for learning through reflection. In H. Mandl \& A. Lesgold (eds.) Learning Issues for Intelligent Tutoring Systems, (1988) pp. 1-18, New York : Springer Verlag.

9. Devi, R., Tiberghien, A, Baker, M., \& Brna, P.: Modelling students' construction of energy models in physics. Instructional Science. (to appear)

10. Dillenbourg, P. \& Self, J.: A computational approach to socially distributed cognition. European Journal of Psychology of Education, 7 (4), (1992) 353-372.

11. Doyle, J.: A Truth Maintenance System. Artificial Intelligence 12. (1979) 231-272.

12. Good, D.A.: The Viability of Conversational Grammars. In M.M. Taylor, F. Néel, D.G. Bouwhuis (Eds.), Human Factors in Information Technology 4, The Structure of Multimodal Dialogue. Amsterdam: Elsevier Science Publishers B.V. (1989)

13. Hoppe, H.U.: The Use of Multiple Student Modeling to Parametrize Group Learning. The Proceedings of Artificial Intelligence in Education, August, Washington, D.C. (1995) 234-249.

14. Joab, M.: Modélisation d'un dialogue pédagogique en langage naturel. (Thése de Doctorat, Université de Paris VI, Paris) (1990).

15. Katz, S. \& Lesgold, A.: The role of the tutor in computer-based collaborative learning situations. In S. Lajoie \& S. Derry (eds.) Computers as Cognitive Tools. Hillsdale NJ : Lawrence Erlbaum Associates (1993).

16. Moeschler, J.: Argumentation et Conversation : Eléments pour une analyse pragmatique du discours. Paris : Crédif-Hatier (1985).

17. Moyse, R. \& Elsom-Cook, M.T.: Knowledge Negotiation. London : Academic Press. (1992)

18. Okamoto, T., Inaba, A., Hasaba, Y.: The Intelligent Learning Support System on the Distributed Cooperative Environment. Proceedings of Artificial Intelligence in Education, August, Washington, D.C. (1995) 588.

19. Paiva, A., Self, J., Hartley, R.: On the Dynamics of Learner Models. Proceedings of ECAI. (1994) 178-182.

20. Sitter, S., \& Stein, A.: Modeling the illocutionary aspects of information-seeking dialogues. Information Processing \& Management. 28 (2) (1992) 165-180.

21. Tiberghien, A. \& Megalakaki, O.: Contribution to a characterisation of a modelling activity case of a first qualitative approach of energy concept. European Journal of Psychology of Education. (to appear)

22. Webb, N.M.: Task Related Verbal Interaction and Mathematical Learning in Small Groups. Research in Mathematics Education. 22 (5) (1991) 366-389. 